\title{
ANALISIS KEBAHAGIAAN GURU DI SD MUHAMMADIYAH KOTA YOGYAKARTA (TINJAUAN DARI ASPEK DUKUNGAN SOSIAL DAN SPIRITUALITAS)
}

\author{
Widi Mulatsih Qona'ah \\ Program Pasca Sarjana \\ Universitas Muhammadiyah Yogyakarta \\ E-mail: mqwidi@gmail.acom
}

\begin{abstract}
Abstrak
Penelitian ini bertujuan untuk mengetahui dan menganalisis bentuk-bentuk kebahagian guru, faktor-faktor pembentuk kebahagiaan guru, wujud dukungan sosial dan spiritual yang mempengaruhi kebahagian guru dan manfaat kebahagiaan yang dirasakan guru di Sekolah Dasar Muhammadiyah kota Yogyakarta. Dalam penelitian ini penulis menggunakan model pendekatan kualitatif dengan teknik analisa Deskriptif Analitik Kualitatif untuk menerangkan fenomena kebahagiaan guru. Hasil dari penelitian ini adalah: yaitu: 1) Bentuk-bentuk kebahagiaan yang dirasakan oleh guru keberhasilan siswa dalam belajar, adanya hobi yang dimiliki guru, dan harapan guru akan meningkatnya tingkat kesejahteraan guru yang diimbangi dengan perjuangan dan usaha keras dalam bekerja; 2) Faktor-faktor pembentuk kebahagiaan guru yaitu interaksi yang baik dengan rekan guru; 3) Wujud dukungan sosial dan spiritualitas yang mempengaruhi kebahagiaan guru di SD Muhammadiyah kota Yogyakarta yaitu (a) dukungan sosial masih sangat dibutuhkan oleh guru. (b) Spiritualitas lebih tinggi ditemukan pada guru dengan usia lebih tua; 4) Guru menjadi lebih mudah bersyukur, guru lebih semangat dalam bekerja, dan guru lebih percaya diri; 5) Guru selalu berusaha untuk berbuat baik kepada Allah SWT.
\end{abstract}

Kata kunci: kebahagiaan, dukungan sosial, spiritualitas

\begin{abstract}
This study aims to determine and analyze the forms of teacher happiness, the factors forming teacher happiness, forms of social and spiritual support that affect teacher happiness and the benefits of happiness felt by teachers at Muhammadiyah Elementary School in Yogyakarta. In this study the authors used a qualitative approach model with Qualitative Analytical Descriptive analysis techniques to explain the phenomenon of teacher happiness. The results of this study are: 1) The forms of happiness felt by the teacher's success in learning, the hobbies owned by the teacher, and the teacher's expectation of an increase in the level of teacher welfare that is balanced with struggle and hard work at work; 2) The factors forming the happiness of the teacher are good interactions with fellow teachers; 3) The form of social support and spirituality that affect the happiness of teachers at Muhammadiyah Elementary School in Yogyakarta, namely (a) social support is still needed by teachers. (b) Higher spirituality is found in older teachers; 4) The teacher becomes easier to be grateful, the teacher is more enthusiastic in working, and the teacher is more confident; 5) The teacher always tries to do good to Allah SWT.
\end{abstract}

Keywords: happiness, social support, spirituality

\section{Info Artikel}

Diterima Januari 2020, disetujui Februari 2020, diterbitkan Juni 2020 


\section{PENDAHULUAN}

Menurut Seligman (2002), kebahagiaan dan kesejahteraan mengacu pada perasaan positif atau emosi positif. Emosi positif ini diklasifikasikan ke dalam tiga kategori yaitu emosi positif yang berkaitan dengan masa lalu meliputi kepuasan, kesenangan, keterkabulan dan kebanggaan; emosi yang berkaitan denganmasa kini kesenangan sesaat (kesenangan jasmanisah) dan kepuasan abadi (aktivitas menyenangkan seperti memancing, mengajar dan berolahraga; dan emosi yang berkaitan dengan masa yang akan datang meliputi optimisme, harapan, kepercayaan diri dan perjuangan.

Al Ghazali berpendapat bahwa hakikat dari kebahagiaan adalah terletak pada pensucian jiwa dari sifat-sifat hina melalui zuhud. Konsep kebahagiaan ini dapat dipahami dari empat aspek yang saling berkait yaitu: 1) mengenal diri, 2) mengenal Allah, 3) mengenal dunia, dan 4) mengenal akhirat. Aspek mengenal diri ini menurut Al Ghazali dapat mengantarkan kepada mengenal Tuhan melalui khazanah keilmuan yaitu konsep cermin diri. Konsep ini berupa usaha manusia untuk mengenal siapa dirinya dan seberapa banyak karat-karat hina yang ada pada dirinya. Berkenaan dengan aspek mengenal dunia, bermaksud agar mencari, mengambil dengan bijak, menyukai, tidak mencela kebaikan di dunia.

Guru dalam aktivitas mengajarnya memiliki kebutuhan tertentu yang harus dipenuhi. Kebutuhan tersebut sesuai pendapat Maslow tentang the hierarchy of needs yang meliputi (1) kebutuhan fisik (physiological needs); (2) kebutuhan akan rasa aman (the safety needs; (3) kebutuhan akan rasa cinta dan memiliki (the belongingness and love needs); (4) kebutuhan akan penghargaan (the esteem needs); dan (5) kebutuhan untuk aktualisasi diri (the needs for self-actualization).

Pandangan Humanistik oleh Maslow ini tidak menjelaskan hubungan antara kebahagiaan dengan pemenuhan kebutuhan hidup, tetapi dapat dikatakan bahwa kehidupan yang baik atau orang yang bahagia adalah ditentukan dari kepuasan seseorang atas terpenuhinya kebutuhan hidupnya dan untuk itu diperlukan lingkungan sosial yang baik pula (lingkungan, pendidikan, pekerjaan, ekonomi). Ini dapat diartikan jika guru tercukupi kebutuhannya akan merasakan kebahagiaan dan kepuasan dalam mengajar. 
Guru dalam mengemban tugasnya tidak mudah, baik guru yang mengajar di wilayah daerah terpencil maupun di wilayah perkotaan. Banyak tantangan dan kesulitan yang dihadapi guru. Guru harus mengorbankan kepentingan dan keselamatan dirinya demi menjalankan amanah tersebut.

Wolmer \& Mills dalam kaitannya dengan undang-undang perlindungan profesi guru mengajukan syarat terhadap profesionalitas guru yaitu: 1) profesi guru harus mendapat dukungan masyarakat; 2) mendapat pengesahan dan perlindungan hukum; 3) memiliki persyaratan kerja yang sehat; 4) mendapat jaminan hidup yang sehat.

Syarat-syarat yang berupa dukungan tersebut sudah selayaknya dipenuhi agar guru bisa menjalankan tugasnya dengan nyaman dan memberi hasil yang maksimal. Perasaan bahagia ini tampak dari karakter positif seperti semangat kerja dan loyalitas tinggi yang ditunjukkan guru ketika sedang bekerja.

Peraturan Pemerintah tentang perlindungan terhadap tenaga kependidikan sebenarnya sudah ada. Dalam pasal 30 UU No.2 Tahun 1989 yang diperkuat lagi UU No.14 Tahun 2005 tentang Guru dan Dosen yang mengatur tentang perlindungan guru dalam melaksanakan tugasnya. Menurut Isjoni, setidaknya ada lima perlindungan hukum bagi tenaga kependidikan, baik guru yang berada di sekolah atau di luar sekolah, yaitu meliputi: (1) rasa aman dalam menjalankan tugasnya; (2) perlindungan dari keadaan yang membahayakan; (3) perlindungan terhadap pemutusan kerja yang sepihak dan merugikan guru; (4) penyelenggaraan usaha kesejahteraan sosial bagi guru, (5) perlindungan terhadap keluarga dalam kondisi apapun.

Dalam penerapannya lima perlindungan hukum tersebut belum sepenuhnya bisa dirasakan oleh guru. Masih banyak keluhan dan ketidakpuasan akan hal-hal yang berkaitan dengan tugas mengajar yang masih dirasakan guru. Masih ada guru yang merasa kurang nyaman dan aman dalam menjalankan tugasnya. Terancamnya keselamatan saat bekerja dan kesejahteraan sosial yang juga masih jauh dari harapan guru.

Sementara syarat-syarat dan hak yang harus diperoleh guru belum sepenuhnya diterima, guru diberi tuntutan ketugasan yang luar biasa berat. Menurut PP No.74/2008 pasal 3 ayat 2, seorang guru dikatakan profesional apabila memenuhi persyaratan kompetensi yang meliputi kompetensi pedagogik, kepribadian, sosial dan profesional. 
Namun kenyataannya, para guru Sekolah Dasar Muhammadiyah sangat berat beban pekerjaannya. Beberapa indikator beratnya beban guru yaitu: 1) jam kerja yang lama; 2) jauhnya jarak tempuh antara sekolah-rumah; 3) Kompetisi antar SD Muhammadiyah; 4) Padatnya agenda kegiatan sekolah.

Dengan padatnya kegiatan guru ini tentu masih menyisakan pertanyaan, apakah guru masih mempunyai harapan untuk bisa mengaktualisasikan diri lebih maksimal lagi, sementara di sisi lain guru sudah terlalu lelah dengan hal-hal yang harus dikerjakan. Bahkan tidak jarang guru lelah secara emosional karena dihadapkan dengan pengalaman negatif yang terkadang muncul baik dengan siswa, rekan sesama guru, maupun orangtua wali murid. Kelelahan emosional ini menurut Pines dan Aronson (1989), adalah kelelahan pada individu yang berhubungan dengan perasaan pribadi yang ditandai dengan adanya perasaan depresi dan tak berdaya. Hal ini jelas, karena dalam profesi pelayanan, guru adalah pekerjaan yang berkaitan erat dengan tuntutan dan pelibatan emosional.

Banyaknya tuntutan dan akumulasi pengalaman negatif akan menambah beban tersendiri bagi guru. Guru akan mengalami kekecewaan, bosan, tertekan, apatis terhadap pekerjaannya dan merasa pekerjaannya sebagai belenggu. Maslach (1993) mengatakan bahwa situasi ini jika terjadi terus menerus bisa menguras sumber energi guru. Sedangkan menurut Sutjipto (2001), seseorang yang mengalami kelelahan emosional akan terkuras sumber-sumber energi emosionalnya sehingga akhirnya tidak bisa memberikan pelayanan secara psikologis. Hal ini tentu membawa dampak tidak baik bagi ketugasan guru di sekolah.

Hal-hal berkenaan dengan kebahagiaan guru dikaitkan dengan aspek dukungan sosial dan spiritualitas yang dibahas dalam penelitian ini. Apakah para guru ini mengalami kebahagiaan dalam mengajar atau sebaliknya.

\section{METODE PENELITIAN}

Penelitian ini menggunakan model pendekatan kualitatif dengan teknik analisa Deskriptif Analitik Kualitatif. Penelitian kualitatif adalah metode berganda yang memfokuskan pada persoalan penelitian yang dikaji yaitu tentang kebahagiaan guru. Metode deskriptif analitik digunakan untuk menerangkan fenomena kebahagiaan guru di SD Muhammadiyah kota Yogyakarta. 
Waktu penelitian pada bulan Desember - Februari 2018 di SD Muh. Kauman, SD Muh. Purwo 2, dan SD Muh. Wirobrajan 2 Yogyakarta. Subyek penelitian adalah 5 guru SD Muhammadiyah yang berada di Kota Yogyakarta. Karakteristik subyek yang dipilih adalah guru dengan masa kerja 5 tahun ke atas, sudah berumah tangga dan memiliki putera, belum bersertifikasi dan tinggal di luar kota Yogyakarta. Metode pengumpulan data dilakukan dengan : a) Pengamatan, b) Wawancara, c) Dokumen, d) Studi Kepustakaan, dan e) Kredibilitas.

Metode analisis data adalah bagian terpenting dalam penelitian karena digunakan untuk memecahkan masalah penelitian. Data mentah yang telah dikumpulkan tersebut ditipologikan dalam kelompok-kelompok dan disaring untuk menjawab permasalahan penelitian.

Adapun langkah-langkah analisis data dalam penelitian ini adalah: 1) reduksi data, yaitu memilih hal-hal pokok, merangkum dan memfokuskan data sesuai dengan tema; 2) penyajian data, dilakukan dalam bentuk uraian singkat maupun bagan. Peneliti kemudian membuat penafsiran terhadap data-data dengan membuat pola-pola dan mencari hubungan antar dua kategori atau lebih. Penafsiran langsung ini akan diberikan untuk memberikan pemaknaan dari masing-masing data temuan yang akan dijabarkan dalam bagian hasil dan pembahasan; 3) penarikan kesimpulan dan verifikasi, kesimpulan yang dikemukakan diawal jika didukung oleh bukti-dan data yang valid akan menjadi kesimpulan yang kredibel

\section{HASIL DAN PEMBAHASAN}

\section{Profil Partisipan}

a. Ibu SR. Usia 37 tahun. Masa kerjanya sudah 11 tahun. SR memiliki 4 putra. Tinggal di Keongan Bantul, sekitar 40 menit ke sekolah (14 km).

b. Ibu RN. Usia 31 tahun. Masa kerja 7 tahun. RN memiliki putri usia 3,5 tahun. Tinggal di Kulon Progo, sekitar 1 jam ke sekolah.

c. Bapak AR. Usia 33 tahun. Masa kerja 10 tahun. AR mempunyai putra usia 8 bulan. Tinggal di Godean Sleman, sekitar 12 km ke sekolah (40 menit).

d. Bapak MA. Usia 48 tahun. Masa kerja 16 tahun. Tinggal di Gamping Kidul Sleman, sekitar 15 menit ke sekolah. MA mempunyai 3 orang putra. 
e. Bapak SG. Usia 42 tahun. Masa kerja 12 tahun. Tinggal di Prambanan, Depok, Sleman, sekitar 50 menit ke sekolah. SG berputra 2 orang.

\section{Bentuk-Bentuk Kebahagiaan Guru di SD Muhammadiyah Kota Yogyakarta}

Beban berat dipikul oleh guru pengampu kelas 6 sekaligus mengampu mata pelajaran UN. Hal ini dirasakan oleh AR. Kemampuan siswa diawal memasuki kelas 6 menjadi perhatian serius bagi guru. Guru harus bisa mengolah berbagai macam potensi dan karakter siswa tersebut agar siap menghadapi ujian. AR berusaha keras untuk mendampingi dan mengarahkan siswanya. Prestasi baik siswa nanti membuatnya bangga dan puas.

Rasa betah dan nyaman di sekolah membuat guru tidak menganggap sekolah sebagai temat bekerja saja. Lebih dari itu, pada responden SG, sekolah menjadi semacam lingkungan di mana beliau bisa mengekspresikan hobinya dengan baik. SG mempunyai hobi bermain sepak bola dan mendapatkan dukungan dari teman lain di sekolahnya.

"Saya dan teman-teman yang putra memang sering ngobrol-ngobrol di sore hari, setelah anak-anak pulang. Kita tidak keburu pulang ya. Kadang-kadang kita sepulang sekolah sering bermain sepak bola. Kita juga kadang mengajak guru dari sekolah lain."

Kebahagiaan guru juga muncul dari adanya harapan atau optimisme akan masa depannya yang baik, terutama agar bisa ikut sertifikasi. Di balik usaha kerasnya dalam mencerdaskan anak bangsa, wajar bila guru ingin mendapatkan haknya secara profesional. Dengan adanya harapan tinggi tersebut guru justru terpacu untuk bekerja lebih giat lagi.

Dari rumusan masalah mengenai bentuk-bentuk kebahagiaan guru, maka dapat dikatakan bahwa bentuk kebahagiaan guru terletak pada: 1) keberhasilan siswa, 2) memiliki hobi, 3) harapan yang tinggi untuk bisa mengikuti sertifikasi, yang diimbangi dengan usaha dan perjuangan yang kuat.

\section{Faktor-Faktor Pembentuk Kebahagiaan Guru}

Kepribadian adalah faktor penting bagi seorang guru, karena kepribadian itulah yang menentukan apakah guru tersebut menjadi pendidik dan pembina yang baik bagi 
siswanya, atau sebaliknya. Hal ini terutama bagi anak-anak yang masih kecil (tingkat sekolah dasar). Kepribadian sesungguhnya adalah bentuk abstrak yang sukar dilihat, namun dapat diketahui dari cara guru dalam tindakannya, ucapannya, caranya bergaul, berpakaian dan dalam menghadapi persoalan baik yang ringan maupun berat.

"Saya orangnya senang bercanda, senang gojeg. Jadi ya... saya kalau mengajar juga selalu disertai humor. Saya kira anak-anak itu juga akan stress ya... kalau kita mengajarnya terlalu tegang."

Salah satu responden laki-laki ini menceritakan bahwa di kelas, beliau sangat menyukai humor. Dengan nuansa humor yang dibangun secara tepat, akan mampu membangkitkan semangat belajar anak. Untuk anak-anak usia Sekolah Dasar, humor yang tepat akan menyenangkan hatinya. Guru menjadi lebih disukai dan ditunggu oleh siswanya. Suasana belajar menjadi ceria. Guru sendiri mengakui, bahwa dengan humor suasana belajar tidak menjadi tegang. Anak-anak tidak dikawatirkan menjadi tertekan karena guru yang kaku atau tidak bisa bercanda.

"Saya orangnya senang bercanda, senang gojeg. Jadi ya... saya kalau mengajar juga selalu disertai humor. Saya kira anak-anak itu juga akan stress ya... kalau kita mengajarnya terlalu tegang."

Salah satu responden laki-laki ini menceritakan bahwa di kelas, beliau sangat menyukai humor. Dengan nuansa humor yang dibangun secara tepat, akan mampu membangkitkan semangat belajar anak. Untuk anak-anak usia Sekolah Dasar, humor yang tepat akan menyenangkan hatinya. Guru menjadi lebih disukai dan ditunggu oleh siswanya. Suasana belajar menjadi ceria. Guru sendiri mengakui, bahwa dengan humor suasana belajar tidak menjadi tegang. Anak-anak tidak dikawatirkan menjadi tertekan karena guru yang kaku atau tidak bisa bercanda.

Situasi di rumah berpengaruh besar dalam membentuk emosi positif guru. Institusi keluarga yang positif, memberikan peluang kepada guru untuk berkarier dengan maksimal, bekerja di luar dengan leluasa. Guru akan merasa nyaman ketika berangkat ke sekolah. Perasaan senang dari rumah ini memberi kemungkinan bagi guru untuk mengembangkan perasaan bahagia ini menjadi semangat kerja yang tinggi untuk bekerja dan mengajar dengan baik. Ketika sudah sampai di sekolah pun, guru merasakan nyaman dan mengajar dengan perasaan gembira. Mengajar lebih bersemangat. 
Dari wawancara dengan kelima responden maka faktor-faktor pembentuk kebahagiaan guru yaitu: 1) adanya interaksi positif dengan rekan guru di sekolah, 2) guru bisa menjalin hubungan timbal-balik yang baik dengan siswa, 3) dukungan dari istri/suami maupun orang tua.

\section{Wujud Dukungan Sosial dan Spiritualitas yang Mempengaruhi Kebahagiaan Guru}

Beratnya pekerjaan guru di sekolah dan jauhnya jarak tempuh sekolah-rumah, membuat jika guru merasakan kelelahan jika sudah sampai di rumah. Beberapa pekerjaan di rumah tidak selesai. Suami RN termasuk yang bisa memaklumi ini, sehingga tidak mempermasalahkan $\mathrm{RN}$ ketika harus pergi ke laundry atau membeli masakan dari luar rumah.

Guru membangun sikap kerjasama dengan pasangan di rumah. Tampak adanya pembagian pekerjaan rumah tangga antara suami dan istri. Pasangan akhirnya bisa menerima aktivitas dan kesibukan suami/istri sebagai guru, yang terkadang sering pulangnya lebih sore, atau justru hari libur harus masuk sekolah. Beberapa guru, baik guru putra maupun putri, mengajak serta anaknya untuk bersekolah di SD tempat guru tersebut mengajar. Dengan demikian sambil bekerja guru tersebut sekaligus momong anaknya sendiri. Hal ini akan lebih membuat nyaman pasangan di rumah, karena ada sebagian ketugasan dalam mendidik anak yang dibantu oleh pasangannya.

Spiritualitas adalah cara individu untuk memahami dirinya dan kebutuhannya secara mendalam dan berkelanjutan agar menjadi lebih baik lagi. Pada guru spiritualitas ini dapat dirasakan dengan adanya semangat guru untuk berkarya, berangkat sekolah dengan semangat, mengerjakan semua tugasnya dengan baik, mengajar dan mendidik siswa dengan sungguh-sungguh.

Pengalaman mengajar selama 16 tahun, membuat beliau penuh dengan pengalaman suka dan duka dalam kehidupan. Beliau akhirnya menyadari bahwa bahwa mengajarlah pekerjaan yang tepat baginya. Kecilnya penghasilan tidak menjadi masalah. Rasa syukur yang tinggi dan selalu ingat Allah membuat nya ikhlas dalam bekerja. Dengan selalu rutin mengkaji ilmu-ilmu agama semakin membangun kedekatan positif dengan Allah SWT. 
Dari wujud dukungan sosial dan spiritualitas bisa diambil kesimpulan yaitu: 1) dukungan keluarga masih sangat dibutuhkan bagi guru-guru dengan usia yang lebih muda, kisaran usia di bawah 40 tahun. Sedangkan bagi guru yang berusia cukup matang yakni 40 tahun ke atas tidak terlalu bergantung pada adanya dukungan dari luar. Mereka akan mampu berdiri sendiri dan mengatur tanggungjawabnya dengan baik; 2) Spiritualitas yang tinggi ditunjukkan pada responden dengan usia yang lebih matang yakni MA. Dengan usianya yang sudah matang MA tampak lebih kentara indikator spiritualitasnya dibandingkan empat responden lain yang lebih muda. Ini tampak pada karakter semeleh, sikap yang merendah, dan bisa memenej ruwetnya ketugasan guru dengan lebih baik daripada guru-guru yang lebih muda.

\section{Manfaat Kebahagiaan Bagi Guru}

Allah berfirman dalam QS. Ar Ra'd ayat 28 yang artinya: “(yaitu) orang-orang beriman dan hati mereka manjadi tenteram dengan mengingat Allah. Ingatlah, Hanya dengan mengingati Allah-lah hati menjadi tenteram." Dengan adanya rasa syukur dan selalu mengingat Allah guru menjadi tenang dan kegiatan belajar menjadi efektif.

Konsep kebahagiaan yang diterapkan secara sungguh-sungguh, menurut $\mathrm{Al}$ Ghazali akan mampu menghasilkan penghayatan berupa takwa, memelihara hubungan dengan Allah dan diri sendiri, sesama manusia dan alam, dengan cara berbuat ihsan, dengan menyadari bahwa Allah selalu mengawasi kita. Rasa bahagia yang dialami guru menurut $\mathrm{Al}$ Ghazali mampu meningkatkan spiritualitas guru. Guru menjalankan tugasnya tidak sekedar pekerjaan fisik semata tetapi berkaitan dengan semangat keTuhanan, yaitu ibadah yang dilakukan dengan bersikap baik dengan siapa saja.

Dari lima responden yang diwawancarai, maka manfaat utama dari rasa bahagia yang dimiliki adalah: 1) Lebih mudah bersyukur kepada Allah; 2) Adanya semangat tinggi dalam bekerja, 3) Guru lebih percaya diri.

\section{KESIMPULAN}

a. Bentuk-bentuk kebahagiaan yang dirasakan oleh guru meliputi: a) keberhasilan siswa dalam belajar, b) adanya hobi yang dimiliki guru, dan c) harapan guru akan meningkatnya tingkat kesejahteraan. 
b. Faktor-faktor pembentuk kebahagiaan guru yaitu: a) interaksi yang baik dengan rekan guru, b) karakter positif guru dalam mengajar sehingga suasana belajar lebih efekif, c) dukungan dari istri/suami dan orangtua.

c. Wujud Dukungan Sosial dan Spiritualitas yang Mempengaruhi Kebahagiaan Guru di SD Muhammadiyah Kota Yogyakarta yaitu, (a) dukungan sosial masih sangat dibutuhkan oleh guru dengan usia di bawah 40 tahun. Sedangkan bagi guru dengan usia di atas 40 tahun sudah tidak terlalu bergantung pada dukungan dari luar. Kematangan usia membuat guru bisa lebih mandiri dalam menjalani ketugasannya tanpa dipengaruhi oleh ada atau tidaknya dukungan dari luar; b) Spiritualitas lebih tinggi ditemukan pada guru dengan usia lebih tua, yang tampak dari sikap merendah, tingkat penerimaan dan pemahaman tentang kehidupan yang lebih baik, lebih sabar, dan kemampuan beradaptasi dengan beratnya ketugasan guru lebih baik dari guru-guru yang lebih muda.

d. Manfaat kebahagiaan guru yaitu: a) Guru menjadi lebih mudah dan merasa lebih dekat dengan Allah SWT., b) Guru merasakan semangat yang tinggi dalam bekerja, c) Guru menjadi lebih percaya diri.

e. Kebahagiaan guru menurut perspektif psikologi Islam yaitu guru yang selalu berusaha untuk berbuat baik kepada Allah SWT. dengan cara: bekerja penuh semangat, dalam mengajar selalu disisipi nilai-nilai keagamaan untuk mendidik siswanya agar berakhlak mulia, berhubungan baik dengan keluarga dan selalu bersyukur..

\section{DAFTAR PUSTAKA}

Carr, A. 2004. Positive Psychology: The Science of Happiness and Human Strength. East Sussex: Brunner Routledge 27 Church Road, Hove.

Churiyah, M. 2011. Pengaruh Konflik Peran, Kelelahan Emosional terhadap Kepuasan Kerja dan Komitmen Organisasi. Malang: FE Univ. Negeri Malang.

Daradjat, Z. 2005. Kepribadian Guru. Jakarta: Bulan Bintang.

Isjoni, 2006. Gurukah Yang Dipersalahkan: Menakar Posisi Guru Di Tengah Dunia Pendidikan Kita. Yogyakarta: Pustaka Pelajar.

Khilmiyah, A. 2016. Metode Penelitian Kualitatif. Yogyakarta: Samudra Biru. 
Muhammad, R., \& Machali, I. 2016. Konseling Islami Menggunakan Konsep Kebahagiaan Al-Ghazali untuk Mereduksi Kesepian pada Konseli di MTs N Bantul Kota Yogyakarta. Jurnal Pendidikan Madrasah. Yogyakarta: Pascasarjana UIN SUKA.

Nurhidayah, S \& Agustini, R. 2012. Jurnal Kebahagiaan Lansia Ditinjau dari Dukungan Sosial dan Spiritualitas. Jurnal Soul Vol.5 No.2 September 